\title{
A comparison between conventional triple therapy and sequential therapy on tolerance of treatment and eradication of Helicobacter pylori infection in Egyptian patients
} Waleed A. Ismail, Ehab F. Mostafa

Department of Internal Medicine,

Gastroenterology and Hepatology Unit, Faculty of Medicine, Zagazig University, Zagazig,

Egypt

Correspondence to Waleed A. Ismail, MD, Department of Internal Medicine, Gastroenterology and Hepatology Unit, Faculty of Medicine, Zagazig University, Zagazig, 44519, Egypt, PO Box 463. Mob: 00201283257001: fax: 0552351164; E-mail: waleed.fattah@yahoo.com

Received 24 January 2018 Accepted 26 March 2018

The Egyptian Journal of Internal Medicine 2018, 30:90-95

\begin{abstract}
Context
Antimicrobial resistance has decreased eradication rates for Helicobacter pylori (H. pylori) infection worldwide. Sequential therapy (ST) has been suggested as an alternative to conventional triple therapy (TT) for the first-line treatment of $H$. pylori. Aim

The purpose of this study was to compare the efficacy and tolerance of levofloxacinbased ST with clarithromycin-based TT.

\section{Materials and methods}

This is a randomized open-label clinical trial carried out on 134 patients with dyspepsia selected from Outpatient Clinic of Hepatology and Gastroenterology Department, Zagazig University Hospital, from October 2015 till September 2016. All patients were $\mathrm{H}$. pylori positive as evidenced by $\mathrm{C} 13$-urea breath test and rapid urease test. Patients were divided into two groups: group I 67 patients received levofloxacin-based ST whereas group II 67 patients received clarithromycin-based TT for 14 days. Eradication rates, drug compliance, and adverse events were compared among the two regimens.

\section{Results}

The intention-to-treat eradication rates were $71.6 \%$ for TT and $91 \%$ for ST $(P=0.004)$. The adverse effects including nausea, vomiting, abdominal pain, and diarrhea were less in levofloxacin-based ST than clarithromycin-based TT, but there was no statistically significant difference (all $P>0.05$ ).

Conclusion

The efficacy of levofloxacin-based ST is significantly better in the treatment of $H$. pylori than TT, and it also shows good tolerability. Countries like Egypt seem to have a high clarithromycin resistance, and a large-scale clinical trial is needed to choose the firstline therapy for eradication of $H$. pylori infection.
\end{abstract}

\section{Keywords:}

conventional triple therapy, Helicobacter pylori infection, sequential therapy

Egypt J Intern Med 30:90-95

(c) 2018 The Egyptian Journal of Internal Medicine

1110-7782

\section{Introduction}

Helicobacter pylori $(H$. pylori) is the main cause of the upper gastrointestinal disorders, which include peptic ulcer disease (gastric and duodenal), chronic gastritis, gastric mucosal-associated lymphoid tissue lymphoma, and gastric cancers [1]. In the latest years, it has been suggested the possible role of $H$. pylori infection with numerous extragastric disorders, which includes neurodegenerative, cardiovascular problems and metabolic, as well as hepatobiliary, pancreatic, and colorectal illnesses. Furthermore, research suggests that this bacterium may be related to the development of skin disorders, which includes urticaria in addition to rheumatic diseases [2]. The most often used strategy is triple therapy (TT). This therapy is composed of a proton pump inhibitor (PPI) (lansoprazole $30 \mathrm{mg} / 12 \mathrm{~h}$, rabeprazole $20 \mathrm{mg} / 12 \mathrm{~h}$, omeprazole $20 \mathrm{mg} / 12 \mathrm{~h}$, esomeprazole $40 \mathrm{mg} / 24 \mathrm{~h}$, or pantoprazole $40 \mathrm{mg} / 12 \mathrm{~h}$ ), amoxicillin $(1 \mathrm{~g} / 12 \mathrm{~h})$, and clarithromycin $(500 \mathrm{mg} / 12 \mathrm{~h})$ taken for 7-14 days. The length of therapy is arguable, even though a meta-analysis cautioned that 14 days gives eradication rates $5 \%$ higher than the ones for 7 days. In cases of hypersensitivity to penicillin, metronidazole is the one of choice to replace amoxicillin, as it is far equally effective and considered equal [3]. Many areas of the world that have been studied on multiple occasions display growing resistance rates to antibiotics in each high and middle/low income countries. A current assessment on the global emergence of $H$. pylori antibiotic resistance confirms that eradication rates have been declining whereas the prevalence of antibiotic resistance rate was growing.

This is an open access journal, and articles are distributed under the terms of the Creative Commons Attribution-NonCommercial-ShareAlike 4.0 License, which allows others to remix, tweak, and build upon the work non-commercially, as long as appropriate credit is given and the new creations are licensed under the identical terms. 
Moreover, clarithromycin resistance rates have now reached 30\% in Italy and Japan, 40\% in Turkey, and $50 \%$ in China, although it is $15 \%$ in Sweden and Taiwan [4]. A recent study in Mansoura Gastroenterology Surgical Centre, Egypt, included 82 patients experi encing upper gastrointestinal symptoms. Biopsy samples have been taken from patients with endoscope and subjected to microbiological culture for $H$. pylori. Antibiotics susceptibility was decided for the isolates to clarithromycin, amoxicillin, metronidazole, cipro floxacin, and levofloxacin, and it was found that there was high occurrence of $H$. pylori strains resistant to clarithromycin (71\%), which was thought to be the primary line antibiotic therapy in treatment of H. pylori; however, resistance patterns had been much less closer to levofloxacin (23.2\%). The study attracts interest that fluoroquinolone resistance is less than that for first-line therapy, which may be a better substitute for first-line antibiotics [5].

Thus, the aim of this study was to compare the efficacy and tolerance of levofloxacin-based sequential therapy (ST) with TT.

\section{Materials and methods}

This is a randomized open-label clinical trial carried out on 134 patients with dyspepsia attending the outpatient clinic of Hepatology and Gastroenterology Department of Zagazig University hospitals from October 2015 to September 2016. They were proved to be $H$. pylori infected as evidenced by using $\mathrm{C} 13$-urea breath test and Campylobacter-like organism (CLO) test. Only patients proved to be $H$. pylori positive in both tests were included in the study. Patients who were less than 18 years old, pregnant or breastfeeding women, patients previously treated with $H$. pylori eradication therapy, patients who previously underwent gastric surgery, and patients with malignant neoplasm were all excluded. All study patients were subjected to detailed medical history and clinical examination, C13-urea breath test, and upper endoscopy with examination of the esophagus, stomach, and duodenum to the second part using Olympus CV150 or Pentax EPM-3500. A rapid urease test (CLO test; Kimberly-Clark Ltd., Draper, Utah, USA) was performed for all patients studied. We obtained biopsy specimens from the antrum and from the corpus of the stomach. When the CLO test showed red-violet color within $24 \mathrm{~h}$ at room temperature, the diagnosis of $H$. pylori infection was made. The study patients were randomly divided into two groups using a table of random numbers:
(1) The first group (67 patients) was randomly assigned to ST in the form of $30-\mathrm{mg}$ proton pump inhibitors (lansoprazole) twice daily and amoxicillin $1 \mathrm{~g}$ twice daily for the first 5 days followed by $30-\mathrm{mg}$ proton pump inhibitors (lansoprazole) twice daily and levofloxacin $500 \mathrm{mg}$ once daily and tinidazole $500 \mathrm{mg}$ twice daily for the second 5 days.

(2) The second group (67 patients) was randomly assigned to $\mathrm{TT}$ in the form of $30-\mathrm{mg}$ proton pump inhibitors (lansoprazole) twice daily and amoxicillin $1 \mathrm{~g}$ twice daily and clarithromycin $500 \mathrm{mg}$ twice daily for 14 days.

We interviewed patients to investigate compliance and the adverse effects of the drugs, including abdominal bloating, abdominal pain, bitter taste, constipation, dizziness, epigastric pain, general weakness, halitosis, headache, diarrhea, loss of appetites, nausea, oral ulcer, skin eruption, sleeping tendency, and vomiting. The term 'less than $80 \%$ compliance' was described as termination of the therapy before the eighth day owing to adverse drug reaction.

Response to treatment was evaluated 6 weeks after cessation of therapy using C13-urea breath test.

This study protocol was conducted in accordance with the provisions of the Declaration of Helsinki and Good Clinical Practice guidelines and was approved by the Institutional Review Board of each participating facility. Informed consent was obtained from all patients.

\section{Statistical analysis}

Statistical package for the social sciences (SPSS) for Windows (version 20; SPSS Inc., Chicago, Illinois, USA). All tests used were two-tailed. A $P$ value less than 0.05 was considered as statistically significant. Continuous data were presented as mean $\pm \mathrm{SD}$. Comparative analysis of continuous data was done using Student's $t$-test. Categorical data were expresses as number (percentage) and summarized in a contingency table. Comparative analysis of categorical $\chi^{2}$ or Fisher's exact test when absolute frequency of any cell in contingency table was greater than or equal to 5 or less than or equal to 5 , respectively. Univariate and multivariate logistic regression analyses were performed for evaluating independent-associated factors with successful H. pylori eradication. 


\section{Results}

There was no significant difference between patients who took ST and those who took TT regarding demographic features: age, sex, smoking, and also clinical presentation (all $P>0.05$; Table 1).

Table 1 Demographic features and clinical presentation of the studied patients $(n=134)$

\begin{tabular}{lccc}
\hline Parameters & $\begin{array}{c}\text { Sequential } \\
(n=67)[n(\%)]\end{array}$ & $\begin{array}{c}\text { Triple } \\
(n=67)[n(\%)]\end{array}$ & $P$ value \\
\hline $\begin{array}{l}\text { Age } \\
\text { Sex }\end{array}$ & $35.05 \pm 8.41$ & $35.64 \pm 10.35$ & 0.715 \\
$\quad$ Male & $35(52.2)$ & $31(46.3)$ & 0.489 \\
$\quad$ Female & $32(47.8)$ & $36(53.7)$ & \\
Smoking & & & \\
$\quad$ Yes & $21(31.3)$ & $20(29.9)$ & 0.851 \\
No & $46(68.7)$ & $47(70.1)$ & \\
Epigastric pain & & & \\
Yes & $41(61.2)$ & $44(65.7)$ & 0.591 \\
$\quad$ No & $26(38.8)$ & $23(34.3)$ & \\
Nausea & & & \\
$\quad$ Yes & $16(23.9)$ & $12(17.9)$ & 0.395 \\
No & $51(76.1)$ & $55(82.1)$ & \\
Vomiting & & & \\
Yes & $17(25.4)$ & $26(38.8)$ & 0.096 \\
No & $50(74.6)$ & $41(61.2)$ & \\
Heart burn & & & \\
$\quad$ Yes & $21(31.3)$ & $18(26.9)$ & 0.568 \\
No & $46(68.7)$ & $49(73.1)$ & \\
Hematemesis & & & \\
Yes & $1(1.5)$ & $65(97)$ & 1 \\
No & $66(98.5)$ & & \\
\hline
\end{tabular}

There was no statistically significant difference between the studied groups according to endoscopic features (all $P>0.05$; Table 2).

Eradication of $H$. pylori was found to be significantly higher in individuals who underwent ST when compared with those who underwent TT $(P<0.05$; Table 3 and Fig. 1).

There was no statistically significant difference between the studied groups according to termination of therapy because of adverse effects ( $P>0.05$; Table 4$)$.

Regarding the adverse effects associated with $H$. pylori treatment, no statistically significant difference was detected between both studied groups (all $P>0.05$; Table 5).

There was a significant positive association between ST and TT in $H$. pylori eradication even after adjustment of other confounding variables (both $P<0.05$; Table 6 ).

Table 2 Endoscopic features of the studied patients $(n=134)$

\begin{tabular}{lccc}
\hline Parameters & $\begin{array}{c}\text { Sequential } \\
(n=67)[n(\%)]\end{array}$ & $\begin{array}{c}\text { Triple } \\
(n=67)[n(\%)]\end{array}$ & $P$ value \\
\hline Antral gastritis & $38(56.7)$ & $40(59.7)$ & 0.726 \\
Pangastritis & $18(26.9)$ & $15(22.4)$ & 0.547 \\
Duodenitis & $9(13.4)$ & $4(6)$ & 0.242 \\
Hiatus hernia & $9(13.4)$ & $6(9)$ & 0.411 \\
GERD & $29(43.3)$ & $20(29.9)$ & 0.106 \\
\hline
\end{tabular}

GERD, gastroesophageal reflux disease.

\section{Figure 1}

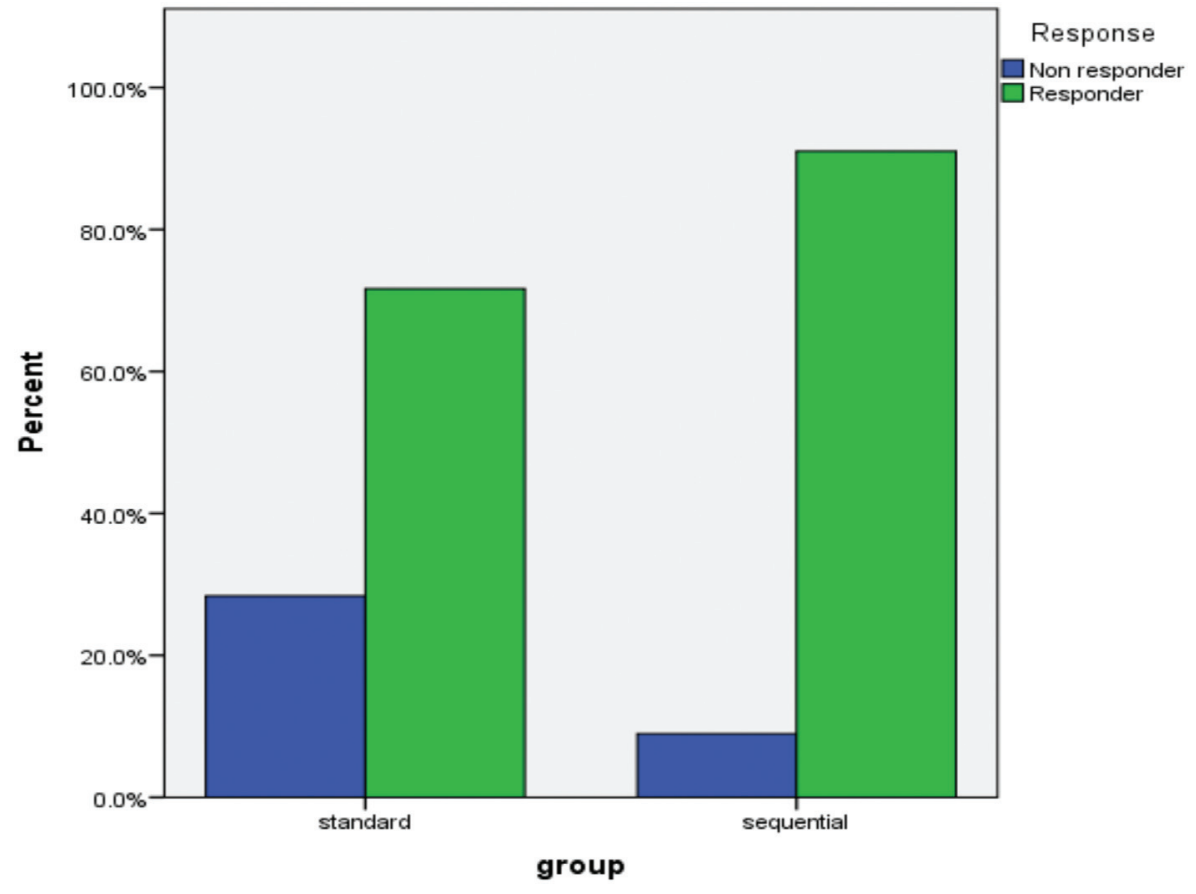

Response to standard triple and sequential therapy. 
Table 3 Response to treatment of Helicobacter pylori by C13urea breath test of the studied patients $(n=134)$ by intentionto-treat analysis

\begin{tabular}{lccc}
\hline Parameters & $\begin{array}{c}\text { Sequential } \\
(n=67)[n(\%)]\end{array}$ & $\begin{array}{c}\text { Triple }(n=67) \\
{[n(\%)]}\end{array}$ & $P$ value \\
\hline Responders & $61(91)$ & $48(71.6)$ & 0.004 \\
Nonresponders & $6(9)$ & $19(28.4)$ & \\
\hline
\end{tabular}

Table 4 Termination of therapy because of adverse effects $(n=134)$

\begin{tabular}{lccc}
\hline Parameter & $\begin{array}{c}\text { Sequential } \\
(n=67)[n(\%)]\end{array}$ & $\begin{array}{c}\text { Triple }(n=67) \\
{[n(\%)]}\end{array}$ & $P$ value \\
\hline $\begin{array}{l}\text { Termination of } \\
\text { therapy }\end{array}$ & $2(3)$ & $3(4.5)$ & 1 \\
\hline
\end{tabular}

Table 5 Adverse effects of the treatment of studied groups $(n=134)$

\begin{tabular}{|c|c|c|c|}
\hline Parameters & $\begin{array}{c}\text { Sequential }(N=67) \\
{[n(\%)]}\end{array}$ & $\begin{array}{c}\text { Standard }(N=67) \\
{[n(\%)]}\end{array}$ & $P$ value \\
\hline \multicolumn{4}{|l|}{ Nausea } \\
\hline Yes & $2(3)$ & $3(4.5)$ & 0.649 \\
\hline No & $65(97)$ & $64(95.5)$ & \\
\hline \multicolumn{4}{|l|}{ Vomiting } \\
\hline Yes & 8 (11.9) & $8(11.9)$ & 1 \\
\hline No & $59(88.1)$ & $59(88.1)$ & \\
\hline \multicolumn{4}{|c|}{ Abdominal pain } \\
\hline Yes & $3(4.5)$ & $4(6)$ & 0.698 \\
\hline No & $64(95.5)$ & $63(94)$ & \\
\hline \multicolumn{4}{|l|}{ Diarrhea } \\
\hline Yes & $4(6)$ & $4(6)$ & 1 \\
\hline No & $63(94)$ & $63(94)$ & \\
\hline
\end{tabular}

Table 6 Association between type of treatment and eradication of Helicobacter pylori $(n=134)$

\begin{tabular}{lccc}
\hline Model & OR & $95 \% \mathrm{Cl}$ of OR & $P$ value \\
\hline Crude & & & \\
Sequential & 4.02 & $1.49-10.86$ & 0.006 \\
$\quad$ Standard & $\mathrm{RC}$ & $\mathrm{RC}$ & $\mathrm{RC}$ \\
Adjusted $^{\mathrm{a}}$ & & & \\
$\quad$ Sequential & 4.09 & $1.48: 11.32$ & 0.007 \\
Standard & $\mathrm{RC}$ & $\mathrm{RC}$ & $\mathrm{RC}$ \\
\hline
\end{tabular}

$\mathrm{Cl}$, confidence interval; OR, odds ratio. ${ }^{\mathrm{a}}$ Adjusted for age and sex. The $r$ by $c$ chi-square test which one of the methods to estimate.

\section{Discussion}

There are very few data about the prevalence of H. pylori infection in Egyptian population. El Dine et al. [6] observed that the general seropositivity for anti- $H$. pylori antibodies was $91.7 \%$, and the rate of infection was different in many age groups, with an increasing fashion in older ages.

Low socioeconomic class, low body weight and height, living in rural areas, and decrease academic fame have been threat factors for the acquisition of H. pylori, and the highest prevalence was within the healthy asymptomatic populace comprising both adults and the pediatric age group in Egypt [7-9].

This high prevalence rate gives an attention to an important question, "what is the most effective treatment regimen?”

In our study, the male and female percentages were 52.2 and $47.8 \%$ in TT group, and 46.3 and $53.7 \%$, in levofloxacin-based ST group, which was not significant, and it is similar to many previous studies ;in which the ratio is insignificant [10-12].

There is no significant difference of $H$. pylori infection between adult men and women [13].

Our study showed that 85 of 134 patients complained of epigastric pain. This was near to the study done by Karthick et al. [14] which was conducted on 100 patients with epigastric pain of gastric origin; 83 of them had dyspepsia, and of them, 61 were $H$. pylori positive $(73.4 \%)$.

Marzio et al. [15] concluded that $H$. pylori infection does not seem to be associated with a specific symptom.

Our study showed that gastritis is the most common endoscopic feature. This agrees with Diab et al. [16] who found a strong association between $H$. pylori infection and patients with gastritis, with existence of $H$. pylori infection in $63(82.9 \%)$ of 74 patients with gastritis.

Chronic H. pylori gastritis affects two-thirds of the world's population [17]. Kyoto global consensus 2015 agrees that the most common cause of chronic gastritis worldwide is infection with $H$. pylori [18].

Our study showed that of 134 patients, 49 patients had gastroesophageal reflux disease (GERD). Corley [19] et al. determined that the presence of antibodies against $H$. pylori had a robust inverse association with GERD symptom frequency and severity. This recommends that if the associations are causal, a portion of the threat for GERD may be related to the absence of gastric colonization with the $H$. pylori bacterium [19].

Rubenstein et al. [20] were unable to detect a negative association between $H$. pylori and GERD symptoms. Grande et al. [21] shows no significant role of $H$. pylori infection in the development of GERD or in the pathogenesis of reflux esophagitis. 
Our study results showed that comparison between conventional TT and levofloxacin-based ST of $H$. pylori showed that eradication of $H$. pylori was found to be significantly higher in individuals who took ST when compared with those who took TT (91 vs. $71.6 \% ; P<0.05$ ).

Maysaa et al. [5] reported in a study done in Mansoura University hospitals, Egypt, that there is a high prevalence of $H$. pylori resistant strains to clarithromycin (71\%), which is thought to be the firstline antibiotic therapy in treatment of $H$. pylori, whereas resistance patterns were less toward levofloxacin (23.2\%) [5].

This is similar to Polat et al. [22] who found that the 10-day ST achieves drastically higher eradication rate that TT $(90 \%$ in sequential versus $57 \%$ in standard therapy groups), with a statistical significance $(P<0.000)$. They concluded that clarithromycin resistance is the main cause of $H$. pylori eradication failure [22].Qian et al. [23] discovered that standard ST produced unacceptably therapeutic efficacy in China. Simplest levofloxacin-containing ST produced a suitable end result [23].

Zullo et al. [24] found that levofloxacin-based sequential treatment has been proved to be better than standard TTs, confirming that the 'sequential' administration of drugs is a successful therapeutic strategy for $H$. pylori infection.

Romano et al. [25] found that in an area with greater than $15 \%$ prevalence of clarithromycin-resistant H. pylori strains, levofloxacin-containing ST is more effective than clarithromycin-containing ST, with 96.8 versus $80.8 \%(P<0.0001)$.

Our study showed that the adverse effects including nausea, vomiting, abdominal pain, and diarrhea are less in levofloxacin ST than standard therapy, but it was of no statistically significant difference (all $P>0.05$ ).

This is similar to Polat et al. [22] and Qian et al. [23] who showed that levofloxacine-based ST is better tolerated than clarithromycine based-TT with better eradication rate.

\section{Conclusion}

Efficacy of levofloxacin-based ST is significantly better in treatment of $H$. pylori than TT, and it also shows good tolerability. Countries like Egypt seem to have a high clarithromycin resistance, and a large-scale clinical trial is needed to choose the first-line therapy for eradication of $H$. pylori infection.

\section{Financial support and sponsorship \\ Nil.}

\section{Conflicts of interest}

There are no conflicts of interest.

\section{References}

1 Hajimahmoodi M, Shams-Ardakani M, Saniee P, Siavoshi F, Mehrabani M, Hosseinzadeh $\mathrm{H}$, et al. In vitro antibacterial activity of some Iranian medicinal plant extracts against Helicobacter pylori. Nat Prod Res 2011; 25:1059-1066.

2 Franceschi F, Gasbarrini A. Helicobacter pylori and extragastric diseases. Best Pract Res Clin Gastroenterol 2007; 21:325-334.

3 Loyd RA, McClellan DA. Update on the evaluation and management of functional dyspepsia. Am Fam Physician 2011; 83:547-552.

4 Thung I, Aramin H, Vavinskaya V, Gupta S, Park JY, Crowe SE, et al. Review article: the global emergence of Helicobacter pylori antibiotic resistance. Aliment Pharmacol Ther 2016; 43:514-533.

5 Maysaa E, Walaa O, Mahmoud A, Ahmed Z. Fluoroquinolone-resistant Helicobacter pylori strains isolated from one Egyptian University Hospital: molecular aspects. J Microbiol Antimicrob Agents 2016; 2:26-31.

6 El Dine S, Mubarak M, Salama R. Low seroprevalence of anti-CagA antibodies inspite of high seroprevalence of anti- $\mathrm{H}$. pylori antibodies in Rural Egyptian Community. Res J Med Sci 2008; 3:118-123.

7 Salem OE, Youssri AH, Mohammad ON. The prevalence of $H$. pylori antibodies in asymptomatic young egyptian persons. J Egypt Public Health Assoc 1993; 68:333-352.

8 Mohammad MA, Hussein L, Coward A, Jackson SJ. Prevalence of Helicobacter pylori infection among Egyptian children: impact of social background and effect on growth. Public Health Nutr 2008; 11: 230-236.

9 Bassily S, Frenck RW, Mohareb EW, Wierzba T, Savarino S, Hall E, et al. Seroprevalence of Helicobacter pylori among Egyptian newborns and their mothers: a preliminary report. Am J Trop Med Hyg 1999; 61: 37-40.

10 Tarkhashvili N, Beriashvili R, Chakvetadze N, Moistsrapishvili M, Chokheli $\mathrm{M}$, Sikharulidze M, et al. Helicobacter pylori infection in patients undergoing upper endoscopy, Republic of Georgia. Emerg Infect Dis 2009; 15: 504-505.

11 Shokrzadeh L, Baghaei K, Yamaoka Y, Shiota S, Mirsattari D, Porhoseingholi A. Prevalence of Helicobacter pylori infection in dyspeptic patients in Iran. Gastroenterol Insights 2012; 4: 24-27.

12 Kaore N, Nagdeo N, Thombare V. Comparative evaluation of the diagnostic tests for Helicobacter pylori and dietary influence for its acquisition in dyspeptic patients: a rural hospital based study in central India. J Clin Diagn Res 2012; 6:636-641.

13 Van Blankenstein M, van Vuuren AJ, Looman CW, Ouwendijk M, Kuipers EJ. The prevalence of Helicobacter pylori infection in the Netherlands. Scand J Gastroenterol 2013; 48:794-800.

14 Karthick P, Sowmya T, Chidambaram K, Natarajan R. Prevalence of disease with epigastric pain with reference to gastric pathology. Internet J Health 2011; 12:2.

15 Marzio L, Cappello G, Ballone E. Evaluation of dyspeptic symptoms in patients with and without Helicobacter pylori infection and normal upper gastrointestinal endoscopy. Dig Liver Dis 2003; 35: $138-142$.

16 Diab M, El-Dine S, Aboul-Fadl L, Shemis M, Omran Z. Helicobacter pylori cag pathogenicity Island genes among dyspeptic patients with chronic gastritis. Egypt J Med Microbial 2009; 18:43-53.

17 Odze RD, Goldblum JR. Surgical pathology of the GI tract, liver, biliary tract, and pancreas. Philadelphia: Elsevier Health Sciences; 2009.

18 Sugano K, Tack J, Kuipers EJ, Graham DY, El-Omar EM, Miura S, et al. Kyoto global consensus report on Helicobacter pylori gastritis. Gut 2015; 64:1353-1367. 
19 Corley DA, Kubo A, Levin TR, Block G, Habel L, Rumore G, et al. Helicobacter pylori and gastroesophageal reflux disease: a case-control study. Helicobacter 2008; 13:352-360.

20 Rubenstein $\mathrm{JH}$, Inadomi JM, Scheiman J, Schoenfeld $\mathrm{P}$, Appelman H, Zhang $\mathrm{M}$, et al. Association between Helicobacter pylori and Barrett's esophagus, erosive esophagitis, and gastroesophageal reflux symptoms. Clin Gastroenterol Hepatol 2014; 12:239-245.

21 Grande M, Lisi G, De Sanctis F, Grande S, Esser A, Campanelli M, et al. Does a relationship still exist between gastroesophageal reflux and Helicobacter pylori in patients with reflux symptoms? World J Surg Oncol 2014; $12: 375$.

22 Polat Z, Kadayifci A, Kantarcioglu M, Ozcan A, Emer O, Uygun A. Comparison of levofloxacin-containing sequential and standard triple therapies for the eradication of Helicobacter pylori. Eur $\mathrm{J}$ Intern Med 2012; 23:165-168.

23 Qian J, Ye F, Zhang J, Yang YM, Tu HM, Jiang Q, et al. Levofloxacincontaining triple and sequential therapy or standard sequential therapy as the first line treatment for Helicobacter pylori eradication in China. Helicobacter 2012; 17:478-485.

24 Zullo A, de Francesco V, Hassan C, Ridola L, Repici A, Bruzzese V, et al. Modified sequential therapy regimens for Helicobacter pylori eradication: a systematic review. Dig Liver Dis 2013; 45:18-22.

25 Romano M, Cuomo A, Gravina AG, Miranda A, lovene MR, Tiso A, et al. Empirical levofloxacin-containing versus clarithromycin-containing sequential therapy for Helicobacter pylori eradication: a randomised trial. Gut 2010; 59:1465-1470. 